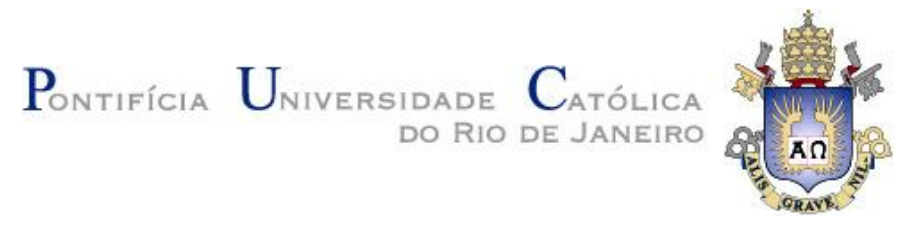

João Paulo Monte de Santana

\title{
O espaço urbano contemporâneo e o \\ sujeito total insurgente
}

Dissertação de Mestrado

Dissertação apresentada ao Programa de PósGraduação em Geografia da PUC-Rio como requisito parcial para obtenção do grau de Mestre em Geografia.

Orientador: Prof. Alvaro Henrique de Souza Ferreira 


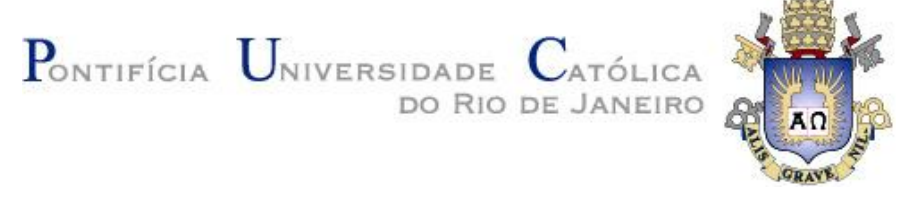

João Paulo Monte de Santana

\title{
O espaço urbano contemporâneo e o sujeito total insurgente
}

\begin{abstract}
Dissertação apresentada ao Programa de PósGraduação em Geografia da PUC-Rio como requisito parcial para obtenção do grau de Mestre em Geografia. Aprovada pela Comissão Examinadora abaixo assinada.
\end{abstract}

Prof. Alvaro Henrique de Souza Ferreira Orientador Departamento de Geografia - PUC-Rio

Prof. João Rua Departamento de Geografia - PUC-Rio

Prof. Luciano Ximenes Aragão Departamento de Geografia - UERJ/FEBF

Profá. Mônica Herz Vice-Decana de Pós-Graduação do Centro de Ciências Sociais- PUC-Rio 
Todos os direitos reservados. É proibida a reprodução total ou parcial do trabalho sem autorização da universidade, do autor e do orientador.

João Paulo Monte de Santana

Graduou-se em Geografia pela Pontifícia Universidade Católica do Rio de Janeiro em 2009. Atualmente leciona a disciplina na educação básica na rede pública estadual.

Ficha catalográfica

Santana, João Paulo Monte de

O espaço urbano contemporâneo e o sujeito total insurgente / João Paulo Monte de Santana; orientador: Alvaro Henrique de Souza Ferreira. - 2013.

114 f.: il. (color.); $30 \mathrm{~cm}$

Dissertação (mestrado)-Pontifícia Universidade Católica do Rio de Janeiro, Departamento de Geografia, 2013.

Inclui bibliografia

1. Geografia - Teses. 2. Sujeito. 3. Totalidade. 4. Produção do espaço. 5. Urbano. 6. Cotidiano. 7. Capitalismo. I. Ferreira, Álvaro. II. Pontifícia Universidade Católica do Rio de Janeiro. Departamento de Geografia. III. Título. 
Para meus pais, por tudo. 


\section{Agradecimentos}

Ao meu caro orientador Alvaro Ferreira por acreditar na realização deste trabalho, pelos conselhos e diálogos estimulantes, e pela paciência e compreensão.

Aos professores que participaram da Comissão examinadora: o Prof. João Rua pelos conselhos e sabedoria geográfica e de vida; o Prof. Luciano Ximenes Aragão pela rica contribuição teórica e análise minuciosa.

A todos os professores da Pós-Graduação, visto que, cada um ao seu modo, foi importante para a minha formação.

À PUC-Rio, onde tive a oportunidade de me reinventar, durante a Graduação, e de redescobrir o mundo acadêmico, agora, na Pós-Graduação.

À turma de mestrado pelas poucas, mas profícuas discussões e debates.

As secretárias do Departamento de Geografia, Márcia e Edna, por toda ajuda que obtive sempre que precisei.

À minha esposa, Priscila, pelo carinho e compreensão. 


\section{Resumo}

Santana, João Paulo Monte de; Ferreira, Alvaro Henrique de Souza. O espaço urbano contemporâneo e o sujeito total insurgente. Rio de Janeiro, 2013. 114 p. Dissertação de Mestrado - Departamento de Geografia, Pontifícia Universidade Católica do Rio de Janeiro.

A presente dissertação busca empreender uma discussão acerca da sociedade contemporânea a partir de uma perspectiva geográfica. Mais precisamente, se debruça sobre a mútua imbricação entre o sujeito e a sociedade que se constituem, enquanto totalidades, por meio do espaço-tempo; o que perpassa necessariamente, no período da globalização onde a cidade e o urbano assumem uma relevância seminal, pela compreensão acerca do espaço urbano no que tange as (inter) ações, múltiplas escalas, mediações, materialidades e representações produzidas e vivenciadas de forma imediata pelo sujeito no cotidiano, sobretudo, através de suas dimensões. No entanto, sob a hegemonia do sistema capitalista, tal dinâmica sócio-espacial é dilacerada ao ser impregnada de relações mercantilistas, individualistas, reducionistas, abstrato-concretas, de dominação e de exploração, desencadeando diversas e intensas problemáticas, conflitos e contradições sociais. De modo a se contrapor e contestar tal ordem totalitária, se objetiva analisar a importância do espaço urbano no processo de concretização do sujeito enquanto totalidade, em meio ao poder alienante/alienado do capital e, ao mesmo tempo, em meio a insatisfações, insurgências e (re) existências teóricas e práticas em face de tal poder hegemônico. Vislumbra-se, assim, o sujeito em concretização e o papel do espaço nesse processo: ora posto como um instrumento fragmentado, homogeneizado e hierarquizado de poder e de alienação imprescindível à reprodução do capital; ora concebido, percebido e vivido como uma via/ elo que possibilita horizontes, como o Direito à Cidade, e a reunião e a apropriação dos elementos materiais e imateriais necessários à reprodução da vida. Em suma, esse é o contexto e o desafio no qual o sujeito total vivência a vida cotidiana em sociedade.

\section{Palavras-chave}

Sujeito; totalidade; produção do espaço urbano; cotidiano; capitalismo. 


\section{Abstract}

Santana, João Paulo Monte de; Ferreira, Alvaro Henrique de Souza (Advisor). The contemporary urban space and the total insurgent subject. Rio de Janeiro, 2013. 114 p. MSc. Dissertation - Departamento de Geografia, Pontifícia Universidade Católica do Rio de Janeiro.

This dissertation undertakes a discussion about contemporary society from a geographical perspective. More precisely, it focuses on the mutual imbrications between subject and society that are constituted, as entities, through space-time, which necessarily permeates the period of globalization where city and urban take over a remarkable importance for the understanding of urban space in relation to (inter) actions, multiple scales, mediation, materiality and representations produced and lived on an immediate way by subject in everyday life, especially through its dimensions. However, under the hegemony of the capitalist system, such a socio-spatial dynamic is destroyed when it is impregnated with mercantilist, individualistic, reductionist, abstract-concrete domination and exploitation relations, triggering numerous and intense problems, social conflicts and contradictions. In order to oppose and challenge such totalitarian order, the objective is to analyze the importance of urban space in the process of composing a subject as an entity, under the alienating / alienated power of capital and at the same time, among the dissatisfaction, insurgencies and (re) theoretical stocks and practices in the face of such a hegemonic power. Thus, it is possible to identify the subject in action and the role of space in this case: sometimes as a fragmented, homogenized and hierarchical instrument of power and alienation essential to the reproduction of capital; sometimes conceived, perceived and lived as a route / link that enables horizons, as the Right to the City, and meeting and appropriation of the tangible and intangible elements necessary for the reproduction of life. In summary, this is the context and the challenge in which the total subject, living a everyday life in society.

\section{Keywords}

Subject; entity; production of urban space; everyday life; capitalism. 


\section{Sumário}

1. Introdução

\section{Apresentação da realidade (Totalidade)}

2. O espaço urbano e o sujeito total em sociedade:

Primeiras aproximações

2.1. Porque o sujeito como categoria analítica?

2.2. O sujeito e o espaço em sociedade: totalidades

na Totalidade concreta

2.3. A (re) produção do espaço de conteúdo urbano:

simultaneidades e contradições da cidade

2.4. O acontecer da cidade como mediação: as múltiplas

e conflituosas escalas no cotidiano

2.5. A (inter) ação social: o elo de conexão, a via de relações conflituosas e a base de concretização dos sujeitos

2.6. Faces da concretização do ser: a prisão e a liberdade

2.7. A concretização do sujeito total no cotidiano do espaço urbano: a mediação e o imediato

2.8. A concretização do sujeito total no cotidiano do espaço urbano: a mediação e as dimensões do ser

Da face alienante/alienada da realidade ...

3. Um olhar sobre o sujeito do/ no espaço urbano no seio da sociedade capitalista: a cidade do Rio de Janeiro como exemplo

3.1. A acumulação e a (re) produção capitalista:

o espaço em questão

3.2. A reprodução capitalista do espaço: em torno

da fragmentação, homogeneização e hierarquização

3.3. A reprodução do espaço capitalista:

em torno da fragmentação, homogeneização

e hierarquização da cidade do Rio de Janeiro

3.4. Contradições do espaço mercadoria:

o exemplo do processo de segregação carioca

3.5. A onipresença do poder do capital: um labirinto de alienações

3.6. A força das alienações física, mental e social 
do sujeito total no cotidiano citadino

... a outra face possível da realidade

4. Um outro olhar sobre o sujeito do/ no espaço urbano no seio da sociedade capitalista: a cidade do Rio de Janeiro como exemplo

4.1. Por que questionar?

4.2. Faces da concretização do ser:

entre determinações e indeterminações

4.3. Para reiniciar a reflexão:

a (i)materialização intencional do espaço pelo sujeito em ação

4.4. O sujeito em sociedade:

entre a objetivação e a subjetivação no espaço-tempo concreto

80

4.5. A busca por (re)existência pelo sujeito

no cotidiano alienante/alienado: o exemplo da favela na cidade

83

4.6. A reprodução da vida entre insatisfações e contestações práticas

e oportunidades e possibilidades teóricas de transgressão

4.7. Rumo ao direito à cidade enquanto um elo às necessidades e reivindicações e um projeto político

4.8. Repensando o papel e a importância das representações para a concretização do sujeito

4.9. Repensando o papel e a importância do outro para a concretização do sujeito

4.10. A luta pelo direito à cidade: a construção de um horizonte democrático através do sujeito total insurgente

5. Considerações finais. O desafio do sujeito total no espaço urbano contemporâneo:

entre múltiplas faces ambíguas, contraditórias e insurgentes

6. Referências 


\section{Lista de ilustrações}

Figura 1

27

Figura 2

63

Foto 1

93 